\title{
PLANO DE GESTÃO DE LOGÍSTICA SUSTENTÂVEL: PROPOSIÇÃO DE AÇÕES E INDICADORES SOCIOAMBIENTAIS PARA AVALIAR O DESEMPENHO NOS ÓRGÃOS PÚBLICOS FEDERAIS
}

\author{
PLAN FOR MANAGEMENT OF SUSTAINABLE LOGISTICS: \\ PROPOSING A LIST OF SOCIAL AND ENVIRONMENTAL \\ INDICATORS FOR PERFORMANCE ASSESSMENT IN PUBLIC \\ AGENCIES OF BRAZILIAN UNION
}

\author{
Data de submissão: $17 / 04 / 2015$ \\ Aceite: $27 / 10 / 2015$ \\ Lilian Campagnin Luiz ${ }^{1}$ \\ Elisete Dahmer Pfitscher ${ }^{2}$ \\ Fabrícia Silva da Rosa ${ }^{3}$
}

\section{RESUMO}

A gestão socioambiental nos órgãos públicos federais brasileiros tornou-se obrigatória com o Decreto n. 7.746/2012, que instituiu a elaboração e implementação do Plano de Gestão de Logística Sustentável (PLS). O PLS foi regulamentado pela Instrução Normativa SLTI/MP n. 10/2012, que determina, além de outros fatores: o conteúdo mínimo a estar contido no PLS, incluindo o Plano de Ações com práticas de sustentabilidade e racionalização no uso de materiais e serviços; os temas mínimos a serem abrangidos; e a forma de avaliação, que deve ocorrer por meio de indicadores. Assim, por se tratar de uma demanda emergente no setor público federal, o presente artigo tem como objetivo geral propor um rol de ações e indicadores para avaliar o desempenho socioambiental nos órgãos públicos federais. Este estudo, de natureza teórica e objetivo-exploratória, é realizado com base em pesquisa bibliográfica para trazer as seguintes contribuições: sugestão de um rol de ações socioambientais passíveis de aplicação nos órgãos públicos federais, com atendimento mínimo aos temas solicitados; elaboração de indicadores para avaliar o desempenho socioambiental nos órgãos públicos federais, nos moldes da instrução normativa regulamentadora; e proposição de uma metodologia para analisar os resultados alcançados.

Palavras-chave: Gestão Socioambiental. Indicadores Socioambientais. Plano de Gestão de Logística Sustentável. Órgãos Públicos Federais.

\footnotetext{
${ }^{1}$ Possui graduação em Ciências Contábeis pela Universidade da Região de Joinville, UNIVILLE e mestrado em Contabilidade pela Universidade Federal de Santa Catarina, UFSC. Blumenau. Santa Catarina. Brasil. E-mail: lilicluiz@gmail.com

${ }^{2}$ Possui graduação em Ciências Contábeis pela Faculdade de Ciências Contábeis e Administrativas de Santa Rosa, FCCASR, mestrado em Engenharia de Produção pela Universidade Federal de Santa Catarina, UFSC e doutorado em Engenharia de Produção pela Universidade Federal de Santa Catarina, UFSC. Atualmente é professora e pesquisadora da Universidade Federal de Santa Catarina. Florianópolis. Santa Catarina. Brasil. E-mail: elisete.dahmer@ufsc.br

${ }^{3}$ Possui graduação em Ciências Contábeis pela Universidade Federal de Santa Catarina, UFSC, mestrado em Engenharia de Produção pela Universidade Federal de Santa Catarina, UFSC, doutorado em Engenharia de Produção pela Universidade Federal de Santa Catarina, UFSC e doutorado em Contabilitade pela Universitat de València, UV, Espanha. Florianópolis. Santa Catarina. Brasil. E-mail: fabriciasrosa@hotmail.com
} 


\section{ABSTRACT}

The environmental management in the agencies of Brazilian Government became mandatory with the introduction of Decree No. 7746/2012, which established the development and implementation of the Plan for Management of Sustainable Logistics (PMSL). The Normative Instruction SLTI/MP No. 10/2012 that regulate the PMSL, defines among others: the minimum content for the PMLS, including the Action Plan with sustainability practices and rational use of materials and services; the least topics to be covered; and the way for evaluation, which must happen with indicators. Thus, once this is an emerging demand in the agencies of Brazilian Government, the main goal of this paper is to propose a list of actions and social and environmental indicators to check the environmental performance in the agencies of Brazilian Government. By its nature, the study is theoretical and with an exploratory goal, and is conducted based on bibliographical research to bring the following contributions: suggest a list of social and environmental actions to be applied in the agencies of Brazilian Government, with minimum attendance to the topics requested in the normative instruction SLTI/MP No. 10/2012; develop a set of indicators to check the environmental performance in the agencies of Brazilian Government, also following the normative instruction SLTI/MP No. 10/2012; and propose a methodology to analyze the achieved results.

Keywords: Social and environmental management. Social and environmental indicators. Plain for Management of Sustainable Logistics. Public agency of Brazilian union.

\section{INTRODUÇÃO}

No século XX, ocorreram transformações significativas em todas as superfícies do globo terrestre e em todas as dimensões da existência humana. Um fator em especial que contribuiu para tais transformações, segundo Maciel e Freitas (2014), consiste nos problemas ambientais globais (aumento da temperatura na terra, destruição da camada de ozônio e esgotamento acelerado dos recursos naturais, por exemplo) que ganharam proporção mundial e passaram a ser alvo de discussões acadêmicas, governamentais e empresariais.

Nesse cenário, Hobsbawm (1996) cita o exponencial desenvolvimento tecnológico, que, ao mesmo tempo em que oferece maior facilidade e comodidade às pessoas, possui grande capacidade de degradação ambiental devido ao descarte prematuro dos produtos e ao crescimento significativo na utilização de matéria-prima e energia para atender às demandas da sociedade. Esta situação se agrava ainda mais com a questão dos resíduos sólidos, que, segundo Widmer (2005), é intensificada com o incremento na geração de resíduos duráveis descartados prematuramente, em especial, produtos eletrônicos e elétricos. Os principais fatores desse incremento, para Cooper (2005), são a rápida inovação tecnológica, a redução da vida útil dos produtos e as novas necessidades e desejos dos consumidores.

Todos os fatores mencionados contribuem para a insustentabilidade ambiental. Em uma tentativa de minimizar os problemas oriundos do descarte indevido dos produtos, o Governo Federal brasileiro instituiu, por meio do Decreto n.o 5.940, de 25 de outubro de 2006 (BRASIL, 2006), que os órgãos da administração pública federal separem os resíduos reciclados descartados e os destinem para associações e cooperativas dos catadores de materiais reciclados. Anos depois, em 2010, o Governo Federal instituiu a Política Nacional de Resíduos Sólidos (PNRS), por meio da Lei n.o 12.305, de 02 de agosto de 2010, uma legislação com abrangência mais ampla que sujeita todas as pessoas físicas e jurídicas a se tornarem responsáveis pela separação adequada dos resíduos sólidos gerados, além de atribuir ao poder público e às empresas a responsabilidade pelo gerenciamento dos resíduos, visando a uma gestão integrada dos mesmos (BRASIL, 2010).

Não apenas a preocupação com os resíduos gerados, mas também todas as circunstâncias que ocasionam a fragilidade e a destruição do meio ambiente instigaram reflexões sobre o 
desenvolvimento e os problemas ocasionados por padrões de vida incompatíveis com o processo de regeneração do meio ambiente, levando ao conceito de desenvolvimento sustentável, um tipo de desenvolvimento que garante a qualidade de vida para as atuais e futuras gerações, sem destruir a base de sustentação: o meio ambiente (BELLEN, 2006).

Entretanto, para operacionalizar o desenvolvimento sustentável, Bellen (2006) destaca a necessidade de desenvolver e aplicar um sistema de indicadores ou ferramentas de avaliação para mensurar a sustentabilidade. Esta prática da gestão socioambiental, segundo Fonseca et al. (2011), já é norma entre as maiores empresas do mundo, que, em resposta às expectativas da sociedade, passaram a avaliar e divulgar periodicamente as informações de natureza econômica, social e ambiental por meio de relatórios de sustentabilidade.

A prática da gestão socioambiental também já é realidade para os órgãos da administração pública federal no Brasil, pois, no final do ano de 2012, o Governo Federal determinou, por meio do Decreto n.o 7.746, de 05 de junho de 2012, que os órgãos da administração pública federal elaborem e implementem o Plano de Gestão de Logística Sustentável (PLS) (BRASIL, 2012). Trata-se de uma ferramenta de planejamento e gestão, com objetivos e responsabilidades definidos, que visa induzir os órgãos ou entidades públicas a estabelecer práticas de sustentabilidade e racionalização de gastos nas atividades desenvolvidas.

A elaboração do PLS foi regulamentada pela Instrução Normativa n. 10, de 12 de novembro de 2012, que determina alguns temas mínimos a serem abrangidos, orienta como elaborar o Plano de Ações Socioambientais e trata sobre a avaliação dos resultados, que deve ocorrer por meio da aplicação de indicadores (BRASIL, 2012). Assim, surge o interesse em investigar: como avaliar o desempenho socioambiental nos órgãos públicos federais?

Dessa forma, o objetivo geral deste estudo consiste em propor um rol de ações socioambientais e os devidos indicadores para avaliar o desempenho socioambiental nos órgãos públicos federais. Como objetivos específicos, busca-se: i) sugerir ações socioambientais passíveis de aplicação nos órgãos públicos federais, com atendimento mínimo aos temas solicitados na Instrução Normativa n.o 10; ii) elaborar indicadores para avaliar o desempenho socioambiental nos órgãos públicos federais, nos moldes da Instrução Normativa n. 10; e iii) propor uma metodologia para analisar os resultados obtidos. A motivação para realizar este estudo decorre do interesse em contribuir para uma padronização de indicadores socioambientais a serem utilizados nos órgãos públicos federais, de modo a permitir a análise comparativa do desempenho socioambiental de diferentes instituições.

Para tanto, o artigo está organizado da seguinte forma: na seção 2, é realizada a revisão teórica que norteia o estudo, com discussões sobre o desenvolvimento sustentável e gestão socioambiental, o PLS e os indicadores socioambientais; na seção 3, é descrita a metodologia da pesquisa; na seção 4, é proposto um rol de ações socioambientais que podem ser aplicadas nos órgãos públicos federais, um conjunto de indicadores para avaliar o desempenho socioambiental nos órgãos públicos federais e uma metodologia para realizar a análise dos resultados obtidos. Para concluir, são apresentadas as considerações finais, limitações e sugestões para futuros estudos.

\section{FUNDAMENTAÇÃO TEÓRICA}

\subsection{Desenvolvimento sustentável e gestão socioambiental}

O termo desenvolvimento sustentável, segundo Bellen (2006), pode ser visto como palavrachave desta época, existindo numerosas formas de conceituá-lo. Todavia, o conceito de desenvolvimento sustentável mais difundido na percepção de Silva, Alves e Volkmer (2014, p. 75) foi o definido 
no Relatório de Brundtland, como "um processo de mudança em que a exploração dos recursos, a direção dos investimentos, a orientação do desenvolvimento tecnológico e a mudança institucional estão todos em harmonia", de modo que as necessidades humanas possam ser satisfeitas atualmente e futuramente (WCDE, 1987, p. 3). Nesse contexto, Teixeira (2013) ressalta que o referido relatório não afasta a necessidade de crescimento econômico, mas busca conciliá-lo com aspectos ambientais e sociais, destacando a urgência de mudança nos padrões de produção e consumo.

Para Jacobi (2003), a ideia de sustentabilidade implica a primazia da premissa de que é preciso definir limites às possibilidades de desenvolvimento, impondo restrições à exploração de recursos naturais, além de orientar o desenvolvimento tecnológico. O referido autor também ressalta a necessidade de delinear um conjunto de iniciativas que considere as dimensões culturais e a existência de interlocutores e participantes sociais relevantes e ativos, por meio de práticas educativas e de um diálogo informado que induzam os indivíduos a constituírem valores éticos e a se sentirem corresponsáveis pelo desenvolvimento sustentável.

Esta condição remete à noção de responsabilidade socioambiental, que, quando transportada para as organizações empresariais, é concebida como "ações e práticas que trazem benefícios para o ambiente, os funcionários, as empresas e, consequentemente, para a sociedade" (SOARES et al., 2014, p. 117). Para tanto, Focht e Abramson (2009) mencionam que as instituições têm o dever de desenvolver e avaliar práticas para restaurar a saúde do sistema produtivo sempre que possível, analisando a forma de melhorar a eficiência na utilização dos recursos naturais e de reduzir os impactos causados no meio ambiente.

Nesse sentido, Dias (2006), Freitas (2013) e Luiz et al. (2013) destacam a necessidade de planejamento e controle das atividades, o que pode ser viabilizado por meio de uma gestão socioambiental definida e estruturada, considerada uma das alternativas mais plausíveis para conduzir uma instituição a alavancar seus índices de desenvolvimento sustentável, por permitir o acompanhamento e a avaliação dos avanços e/ou do retrocesso resultantes de suas atividades.

O primeiro passo para implementar um sistema para gestão ambiental, segundo Engelman, Guisso e Fracasso (2009), é fazer uma avaliação sobre a interação da organização com o meio ambiente, por meio de um inventário de ocorrências e das condições de funcionamento das atividades, incluindo a análise da legislação pertinente. Na determinação das ações, devem-se considerar todas as atividades envolvidas e seus respectivos impactos ambientais. Ademais, a implementação requer mudança comportamental e gerencial na organização e deve ser conduzida de modo participativo e integrado.

Grosbois (2012) aponta que, nas últimas duas décadas, muitas organizações passaram a implementar iniciativas de sustentabilidade em suas operações e divulgar informações sobre o escopo e a eficácia dessas iniciativas. Dessa forma, os relatórios de sustentabilidade passam a integrar a prestação de contas de muitas empresas, como fonte informativa da responsabilidade socioambiental organizacional. Nos órgãos públicos federais brasileiros, esta iniciativa também está sendo implementada, em decorrência de um decreto governamental que obriga tais instituições a desenvolverem e implementarem o PLS, assunto este abordado na subseção seguinte.

\subsection{Plano de Gestão de Logística Sustentável (PLS)}

A logística é compreendida por Oda et al. (2009) como parte do gerenciamento da cadeia de abastecimento, englobando planejamento, controle do fluxo e armazenamento eficiente e econômico de materiais. Para os autores, a logística pode ser sustentável se, inserida como parte da gestão estratégica das organizações e no conjunto da cadeia, reduzir danos e impactos negativos na gestão.

Para Farias et al. (2013), a logística sustentável é um conceito que contribui para for- 
matar uma estratégia de criação de valor sustentável que inclui a redução do consumo de matéria-prima e da emissão de poluentes (podendo ser observada no contexto de reutilização de produtos), o nível de transparência e responsabilidade socioambiental, o desenvolvimento de novas tecnologias e o atendimento às demandas do mercado e da sociedade em que se insere.

Buscando internalizar o conceito de logística sustentável nos órgãos públicos federais, o governo instituiu, por meio do Decreto n. 7.746, de 05 de junho de 2012, o PLS (BRASIL, 2012). O objetivo desse Decreto é estabelecer critérios, práticas e diretrizes para promover o desenvolvimento sustentável nacional, por meio de aquisições e contratações de serviços e obras na administração pública federal.

As regras para a elaboração do PLS foram normatizadas pela Instrução Normativa n.o 10, de 12 de dezembro de 2012, que traz: definições; atribuição de responsabilidade pela implementação; orientações sobre o conteúdo mínimo a compor o PLS; temas mínimos a serem abrangidos; tópicos para estruturação do Plano de Ações; e modo de construir os indicadores para avaliação da sustentabilidade. Determina, ainda, a necessidade de capacitações, divulgação do PLS, elaboração do relatório de acompanhamento e seu envio (em formato eletrônico) para a Secretaria Executiva da Comissão Interministerial de Sustentabilidade na Administração Pública (CISAP) (BRASIL, 2012).

Os conteúdos mínimos a estarem contidos no PLS, conforme determina a Instrução Normativa n.o 10 são: atualização de inventário de bens e materiais do órgão e identificação de similares de menor impacto para substituição; práticas de sustentabilidade e de racionalização no uso de materiais e serviços; responsabilidades, metodologia de implementação e avaliação do plano; e ações de divulgação, conscientização e capacitação (BRASIL, 2012).

Sobre as práticas de sustentabilidade e de racionalização no uso de materiais e serviços, a Instrução Normativa n. 10, em seu art. 8으, determina que, no mínimo, os seguintes temas devem ser abrangidos no PLS: material de consumo (pelo menos papel e cartuchos para impressão e copos descartáveis); energia elétrica; água e esgoto; coleta seletiva; qualidade de vida no ambiente de trabalho; compras e contratações sustentáveis (pelo menos obras, equipamentos, serviços de vigilância, limpeza, telefonia, processamento de dados, apoio administrativo e manutenção predial); e deslocamento de pessoal (todos os meios de transporte, com foco na redução de gastos e emissão de substâncias poluentes) (BRASIL, 2012). Nota-se aqui a inclusão no PLS da temática "qualidade de vida no ambiente de trabalho", o que denota que, além de questões ambientais, o PLS deve prever questões de natureza social.

Para cada uma das temáticas a serem incluídas no PLS, a instituição deve construir um Plano de Ações, identificando seu objetivo; detalhando as ações a serem implementadas; definindo as unidades e as áreas envolvidas na implementação e os responsáveis pela execução de cada ação; estabelecendo o cronograma de implementação de cada ação e as metas a serem alcançadas para cada uma; e estimando a previsão de recursos financeiros, humanos, instrumentais etc., necessários para a implementação das ações (BRASIL, 2012).

Para auxiliar na elaboração do PLS, a Instrução Normativa n.o 10 sugere alguns programas e iniciativas governamentais que podem ser observados (BRASIL, 2012). Dentre eles, está a Agenda Ambiental na Administração Pública (A3P), um programa desenvolvido pelo Ministério do Meio Ambiente (MMA) que tem o propósito de instigar a revisão dos padrões de produção e consumo e a adoção de novos referenciais em busca da sustentabilidade socioambiental no âmbito da administração pública, independente da esfera (MMA, 2009). Para isso, as ações socioambientais norteadas pela A3P são definidas em observância a seis eixos temáticos prioritários, conforme apresentado no Quadro 1. 
Quadro 1 - Eixos temáticos da A3P

\begin{tabular}{|c|c|c|}
\hline Eixo temático & Implicação & Ações \\
\hline $\begin{array}{l}\text { Uso racional } \\
\text { dos recursos }\end{array}$ & Evitar o desperdício. & $\begin{array}{c}\text { Usar racionalmente energia elétrica, água, madeira, copos, } \\
\text { plásticos, materiais de expediente etc., reduzindo o consumo } \\
\text { e combatendo o desperdício. }\end{array}$ \\
\hline $\begin{array}{l}\text { Gestão de resí- } \\
\text { duos }\end{array}$ & $\begin{array}{l}\text { Destinar corretamente } \\
\text { os resíduos gerados. }\end{array}$ & $\begin{array}{l}\text { Reduzir a geração de resíduos, aumentar a reciclagem e reu- } \\
\text { tilização dos resíduos sólidos e destinar adequadamente os } \\
\text { rejeitos. }\end{array}$ \\
\hline $\begin{array}{l}\text { Qualidade de } \\
\text { vida no am- } \\
\text { biente de tra- } \\
\text { balho }\end{array}$ & $\begin{array}{c}\text { Facilitar e satisfazer } \\
\text { as necessidades do } \\
\text { trabalhador e respeitar } \\
\text { seus direitos e suas } \\
\text { opiniões. }\end{array}$ & $\begin{array}{l}\text { Melhorar as condições ambientais, promover a saúde e se- } \\
\text { gurança, observar o acesso aos portadores de deficiências } \\
\text { físicas, incentivar a integração social, usar e desenvolver as } \\
\text { capacidades humanas, aproveitando as habilidades de cada } \\
\text { um, dar autonomia para o servidor desempenhar sua função } \\
\text { e respeitar a liberdade de expressão e privacidade pessoal. }\end{array}$ \\
\hline $\begin{array}{l}\text { Sensibilização } \\
\text { e capacitação } \\
\text { dos servidores }\end{array}$ & $\begin{array}{l}\text { Mudar os hábitos, o } \\
\text { comportamento e os } \\
\text { padrões de consumo. }\end{array}$ & $\begin{array}{c}\text { Desenvolver e consolidar nos servidores, sobretudo nos gesto- } \\
\text { res, a consciência cidadã da responsabilidade socioambiental } \\
\text { por meio da capacitação (palestras, minicursos, apresenta- } \\
\text { ções, fóruns etc). }\end{array}$ \\
\hline $\begin{array}{l}\text { Licitação Sus- } \\
\text { tentável }\end{array}$ & $\begin{array}{l}\text { Promover a responsa- } \\
\text { bilidade socioambien- } \\
\text { tal nas compras. }\end{array}$ & $\begin{array}{l}\text { Incluir nos editais de licitações, com o máximo de detalhes } \\
\text { possíveis, a descrição de produtos sustentáveis, levando em } \\
\text { consideração aspectos relacionados à capacidade técnica e } \\
\text { econômico-financeira do licitante, à qualidade do produto e } \\
\text { ao valor do objeto. }\end{array}$ \\
\hline $\begin{array}{l}\text { Construções } \\
\text { sustentáveis }\end{array}$ & $\begin{array}{c}\text { Minimizar impactos } \\
\text { sobre o meio am- } \\
\text { biente e promover a } \\
\text { economia de recursos } \\
\text { naturais. }\end{array}$ & $\begin{array}{c}\text { Analisar o ciclo de vida do empreendimento e os materiais a } \\
\text { serem utilizados, reaproveitar materiais para reduzir o consu- } \\
\text { mo de recursos naturais, aproveitar os recursos naturais como } \\
\text { energia solar e correntes de vento e utilizar materiais com } \\
\text { certificado de origem. }\end{array}$ \\
\hline
\end{tabular}

Fonte: elaborado por Luiz et al. (2013), com base em MMA (2009; 2015).

Dos seis eixos temáticos da A3P, apenas a "sensibilização e capacitação" não consta como tema mínimo a ser incluído no PLS dos órgãos públicos federais; porém, consta como conteúdo mínimo do mesmo, juntamente com as ações de divulgação. É importante observar que os temas mínimos dizem respeito aos tópicos ou assuntos que devem ser abordados/medidos no PLS, enquanto que o conteúdo mínimo se refere ao que deve estar contemplado nesse Plano. Por entender que as ações de sensibilização e capacitação são fundamentais para a boa execução das demais ações implementadas em cada temática do PLS, neste estudo, as questões de sensibilização e capacitação serão tratadas como tema, de modo que serão sugeridos indicadores e ações pertinentes à temática.

A Figura 1, a seguir, ilustra a consonância existente entre os temas mínimos a serem abordados no PLS e os respectivos eixos da A3P. 
Figura 1 - Eixos temáticos da A3P versus temas mínimos do PLS

Uso Racional dos Recursos

Fonte: elaborado pelos autores, com base em MMA (2015) e Brasil (2012).

Para realizar a avaliação da sustentabilidade no que concerne aos temas mínimos do PLS, a Instrução Normativa n. -10 determina que os resultados sejam mensurados com base em indicadores, os quais devem conter: nome, fórmula de cálculo, fonte de dados, metodologia de apuração e periodicidade de apuração (BRASIL, 2012). O objetivo da mensuração, segundo Bellen (2006), é auxiliar os tomadores de decisão na avaliação de seu desempenho em relação às metas estabelecidas, fornecendo bases para o planejamento de futuras ações. Nesse processo, os indicadores são uma importante ferramenta, pois, por seu intermédio, será possível monitorar os progressos da sociedade rumo ao desenvolvimento sustentável.

\subsection{Indicadores socioambientais}

Os indicadores "são medidas que podem ser usadas para ilustrar e comunicar fenômenos complexos de uma forma simples, incluindo tendências e progressos ao longo do tempo" (UNEP, 2012, p. 51, tradução nossa). Seu objetivo, segundo Bellen (2006), é agregar e quantificar informações a fim de tornar a significância destas mais aparente, pois eles simplificam informações complexas, tentando melhorar o processo de comunicação.

Campos e Melo (2008) ressaltam que os indicadores são vitais para monitorar os processos quanto ao alcance ou não de uma meta ou de um padrão de desempenho estabelecido, pois, com o acompanhamento dos dados, é possível identificar os desvios de percurso e suas prováveis causas, para, então, propor ações de melhoria. Nesse sentido, Tunstall (apud GALLOPíN, 1996, p. 109, tradução nossa) destaca como principais funções de um indicador:

- Avaliar as condições e tendências;

- Efetuar comparações entre lugares e situações;

- Avaliar as condições e tendências em relação aos objetivos e às metas;

- Fornecer informações de advertência; 
- Antecipar as condições e tendências futuras.

Todavia, para a eficácia na aplicação de um indicador, Gallopín (1996) destaca a necessidade de transparência e compreensibilidade dos indicadores, pois estes são meios de comunicação e, como tal, precisam ser entendidos pelos participantes do processo. Desse modo, os usuários devem ser estimulados a compreender seu significado e sua significância dentro do processo.

Os indicadores podem ser quantitativos ou qualitativos. Gallopín (1996) explicita que é preferível a utilização de indicadores qualitativos quando houver indisponibilidade de informações quantitativas, o atributo de interesse não for quantificável ou os custos para isso não justificarem os benefícios proporcionados. Pereira (2001) destaca que um evento qualitativo pode ser medido por variáveis qualitativas e quantitativas. Para o autor, os dados qualitativos implicam a perda de precisão da medida, mas não necessariamente a perda de acurácia, pois, muitas vezes, são capazes de representar melhor o evento estudado.

Para a implementação de um sistema de indicadores de desenvolvimento sustentável, Gallopín (1996) e Bellen (2006) sugerem observância a alguns requisitos universais: os valores dos indicadores devem ser mensuráveis (ou observáveis); deve haver disponibilidade dos dados; a metodologia para a coleta, o processamento dos dados e a construção dos indicadores deve ser limpa, transparente e padronizada; deve existir disponibilidade dos meios (capacidade financeira, humana e técnica) para construir e monitorar os indicadores; os indicadores ou grupo de indicadores devem ser financeiramente viáveis; e deve haver aceitação política dos indicadores no nível adequado, pois indicadores não legitimados pelos tomadores de decisão são incapazes de influenciar as decisões. Gallopín (1996) também aponta a participação como um pré-requisito fundamental para a utilização e aceitação de um sistema de indicadores, pois tal elemento reforça a legitimidade do sistema, a construção do conhecimento e a consciência sobre a realidade ambiental.

Nesse contexto, Krajnc e Glavic (2003) explicam que cada indicador tem de refletir as características específicas da empresa/organização e deve ser definido de acordo com os objetivos, a estratégia e as metas da organização, bem como estar alinhado a esses quesitos, para proporcionar maiores vantagens. 


\section{METODOLOGIA DA PESQUISA}

O desenvolvimento de um estudo é caracterizado pela sua metodologia e pelos métodos utilizados. Para Richardson (2008, p. 22), "método é o caminho ou a maneira para chegar a determinado fim ou objetivo", enquanto que "metodologia são os procedimentos e regras utilizadas por determinado método". Com base nessa concepção, apresenta-se, no Quadro 2, a metodologia da pesquisa.

Quadro 2 - Metodologia da pesquisa

\begin{tabular}{|c|c|c|}
\hline $\begin{array}{c}\text { Aspecto } \\
\text { pesquisa da }\end{array}$ & Classificação & \multicolumn{1}{c|}{ Descrição/referência } \\
\hline Objetivos & Exploratório & $\begin{array}{l}\text { A pesquisa teórica contribui para avançar no conhecimento sobre } \\
\text { determinada teoria, aprimorando fundamentos teóricos e indire- } \\
\text { tamente aprimorando práticas (RIBEIRO, 2011). }\end{array}$ \\
\hline $\begin{array}{c}\text { Procedimentos } \\
\text { como objetivo proporcionar maior familiaridade com o problema } \\
\text { para torná-lo mais explícito. Raupp e Beuren (2009) entendem que } \\
\text { este tipo de pesquisa ocorre quando há pouco conhecimento so- } \\
\text { bre a temática a ser abordada e o pesquisador busca conhecer o } \\
\text { assunto com mais profundidade para torná-lo mais claro ou cons- } \\
\text { truir questões importantes para conduzir o estudo. }\end{array}$ \\
\hline $\begin{array}{c}\text { Abordagem } \\
\text { problema }\end{array}$ & Pesquisa bi- \\
bliográfica & $\begin{array}{l}\text { A pesquisa bibliográfica, segundo Gil (2007), busca explicar um } \\
\text { problema com base em materiais já elaborados. }\end{array}$ \\
\hline & $\begin{array}{l}\text { Utilizada no intuito de explicar o porquê das coisas, valendo-se } \\
\text { de diferentes abordagens que podem ser interpretadas global e } \\
\text { individualmente (RIBEIRO, 2011), a pesquisa qualitativa possibili- } \\
\text { ta, ainda, fazer uma análise mais profunda sobre o fenômeno que } \\
\text { está sendo estudado (RAUPP; BEUREN, 2009). }\end{array}$ \\
\hline
\end{tabular}

Fonte: elaborado pelos autores.

A obrigatoriedade da gestão socioambiental nos órgãos públicos federais brasileiros é relativamente recente. Por essa razão, para o desenvolvimento deste estudo, o método utilizado consiste, quase em sua totalidade, na consulta a referências bibliográficas, tais como: livros, artigos, legislações, programas governamentais, dissertações e teses. Outro fator que contribuiu para a proposição das ações socioambientais e dos indicadores socioambientais é a experiência e atuação dos autores no serviço público federal, os quais possuem envolvimento direto com pesquisas e grupos de estudo que têm como foco a sustentabilidade socioambiental.

Visando à aplicabilidade do estudo, busca-se dar ênfase às normas estabelecidas para a implementação do PLS nos órgãos públicos federais, bem como às ações socioambientais que podem ser aplicadas em tais órgãos e aos indicadores socioambientais para mensurar o desempenho. Para a proposição das ações e dos indicadores socioambientais, utilizam-se como base estrutural os seis eixos temáticos da A3P pelos seguintes motivos: no ano de 2002, a A3P foi reconhecida pela Organização das Nações Unidas para a Educação, a Ciência e a Cultura (UNESCO) como "o melhor dos exemplos" na categoria meio ambiente (MMA, 2009); a A3P foi incluída no Plano Plurianual (PPA) do Governo Federal 2004/2007 e 2008/2011 como ação integrante do programa de Educação Ambiental para Sociedades Sustentáveis, garantindo recursos para viabilizar sua efetiva implantação, o que a tornou um referencial de sustentabilidade na administração pública (MMA, 2009); e todos os temas mínimos a serem incluídos no PLS estão contidos nos seis eixos do programa A3P. 


\section{PROPOSIÇÃO DE AÇÕES E INDICADORES SOCIOAM- BIENTAIS PARA APLICAÇÃO NOS ÓRGAOS PÚBLICOS FEDERAIS}

Como verificado na fundamentação teórica, os órgãos da administração pública federal brasileira estão obrigados a desenvolver e implementar o PLS, atendendo, no mínimo, aos seguintes temas: material de consumo; energia elétrica; água e esgoto; coleta seletiva; qualidade de vida no ambiente de trabalho; compras e contratações sustentáveis; e deslocamento de pessoal.

Além disso, um dos conteúdos mínimos a compor o PLS dos órgãos públicos federais consiste nas práticas de sustentabilidade e de racionalização no uso de materiais e serviços, organizados em um Plano de Ações para cada temática. Esse Plano de Ações deve conter o objetivo, o detalhamento das ações a serem implementadas, a definição das áreas envolvidas na execução de cada ação, os responsáveis pela implementação, as metas a serem alcançadas para cada ação, o cronograma de implementação e a previsão de recursos financeiros, humanos, instrumentais, dentre outros. Assim, seguindo a estruturação dos seis eixos temáticos da A3P, apresentam-se, no Quadro 3, algumas ações socioambientais passíveis de aplicação nos órgãos públicos federais.

Quadro 3 - Sugestão de ações socioambientais para o Plano de Ações do PLS

\begin{tabular}{|c|c|}
\hline Eixo temático & Ações socioambientais \\
\hline $\begin{array}{l}\text { Uso racional dos } \\
\text { recursos }\end{array}$ & $\begin{array}{l}\text { Imprimir documentos em frente e verso e em modo rascunho; sempre que possível, } \\
\text { arquivar documentos em meio eletrônico; revisar documentos antes de imprimir; } \\
\text { implementar sistema de cobrança para cópias particulares; reaproveitar papeis im- } \\
\text { pressos apenas de um lado para confeccionar blocos de rascunho; utilizar lâmpadas } \\
\text { econômicas; utilizar o ar-condicionado apenas quando necessário; desligar as luzes e } \\
\text { os equipamentos ao ausentar-se do ambiente; instalar sensores de presença em locais } \\
\text { onde há trânsito de pessoas; utilizar torneiras com fechamento automático e redutor } \\
\text { de vazão; utilizar válvulas de descarga com duas opções de acionamento; adquirir mic- } \\
\text { tórios com tecnologia a seco; racionar a lavação dos veículos oficiais; substituir copos } \\
\text { descartáveis por copos de vidro ou garrafas pet; planejar e organizar o deslocamento } \\
\text { de servidores para reduzir/otimizar viagens; adquirir veículos flex e econômicos; dar } \\
\text { preferência para realizar reuniões via videoconferência; utilizar adequadamente os } \\
\text { equipamentos e realizar manutenção periódica para prorrogar sua vida útil; realizar } \\
\text { manutenção predial preventiva; disponibilizar os bens inutilizados etc. }\end{array}$ \\
\hline $\begin{array}{l}\text { Gestão de } \\
\text { resíduos }\end{array}$ & $\begin{array}{l}\text { Formar comissão de coleta seletiva no órgão; adquirir coletores específicos para des- } \\
\text { carte dos resíduos gerados; organizar depósito para armazenar os resíduos descartados } \\
\text { até que seja realizada sua coleta; orientar para que os resíduos orgânicos sejam enca- } \\
\text { minhados para compostagem; destinar adequadamente os resíduos perigosos; definir e } \\
\text { operacionalizar a coleta seletiva; aumentar a reutilização dos resíduos sólidos etc. }\end{array}$ \\
\hline $\begin{array}{c}\text { Qualidade de } \\
\text { vida no ambiente } \\
\text { de trabalho }\end{array}$ & $\begin{array}{l}\text { Avaliar a salubridade dos ambientes; analisar a ergometria dos móveis; manter a hi- } \\
\text { giene no ambiente físico; adaptar as instalações para permitir o acesso de pessoas } \\
\text { com necessidades específicas; avaliar a satisfação dos servidores; tratar igualmente } \\
\text { os servidores e respeitar as particularidades de cada um; respeitar os direitos do ser- } \\
\text { vidor; proporcionar a realização de exames periódicos; aproveitar as habilidades de } \\
\text { cada um; promover eventos para integrar os servidores; organizar ginástica laboral; } \\
\text { nomear Comissão Interna para Prevenção de Acidentes etc. }\end{array}$ \\
\hline
\end{tabular}




\begin{tabular}{|c|l|}
\hline $\begin{array}{c}\text { Sensibilização e } \\
\text { capacitação dos } \\
\text { servidores }\end{array}$ & $\begin{array}{l}\text { Sensibilizar e capacitar os gestores, servidores, contratados, terceirizados e estagiários } \\
\text { sobre o uso racional dos recursos naturais, a coleta seletiva e as licitações sustentá- } \\
\text { veis; divulgar informações sobre a temática socioambiental; e, no caso das escolas, } \\
\text { incluir a temática socioambiental nas ementas das disciplinas, realizar e estimular pes- } \\
\text { quisas e promover eventos de extensão. }\end{array}$ \\
\hline $\begin{array}{c}\text { Licitação } \\
\text { sustentável }\end{array}$ & $\begin{array}{l}\text { Avaliar a real necessidade de aquisição de produto e/ou contratação de serviço; obser- } \\
\text { var a certificação dos equipamentos e móveis de madeira; observar a vida útil dos bens; } \\
\text { adquirir computadores com tela LCD; dar preferência para a realização de compras/con- } \\
\text { tratações compartilhadas; priorizar as aquisições/contratações de origem local etc. }\end{array}$ \\
\hline $\begin{array}{c}\text { Construções } \\
\text { sustentáveis }\end{array}$ & $\begin{array}{l}\text { Nas obras, aproveitar ao máximo a iluminação solar e ventilação natural; instalar re- } \\
\text { servatórios para captar a água da chuva; instalar sensores de presença nas áreas co- } \\
\text { muns; priorizar a instalação de aquecedor solar ou painel voltaico para geração de } \\
\text { energia; instalar isolante térmico para reduzir o calor do ambiente; pintar o ambiente } \\
\text { interno com cores claras para reduzir a necessidade de iluminação artificial; priorizar } \\
\text { contratações de origem local etc. }\end{array}$ \\
\hline
\end{tabular}

Fonte: MMA (2009), Timossi (2009), Almeida (2010) e Brasil (2010; 2012).

A despeito da heterogeneidade presente nas ações e atividades desenvolvidas nos diferentes órgãos da administração pública (por exemplo: atividade-fim voltada para a área da saúde, da educação, da segurança, da assistência social etc.), salienta-se que as sugestões de ações socioambientais apresentadas no Quadro 3 são comuns à maioria dos órgãos públicos federais, porém não esgotam todas as possibilidades. Desse modo, cabe a cada órgão analisar suas atividades e os impactos causados no ambiente onde está inserido, para, então, construir seu Plano de Ações de acordo com suas peculiaridades.

Após a definição do Plano de Ações Socioambientais a ser implementado no órgão, procede-se à deliberação dos indicadores para avaliar o desempenho socioambiental. Nesta etapa, seguindo a mesma lógica de análise da atividade-fim desenvolvida por cada órgão público, serão definidos os indicadores relevantes a serem implantados. Para a construção dos indicadores, a Instrução Normativa $\mathrm{n}$. o 10 determina que estes devem conter nome, fórmula de cálculo, fonte de dados, metodologia de apuração e periodicidade de apuração (BRASIL, 2012). Do mesmo modo que para os seis eixos temáticos da A3P, sugere-se um rol de indicadores socioambientais, conforme exposto no Quadro 4. 


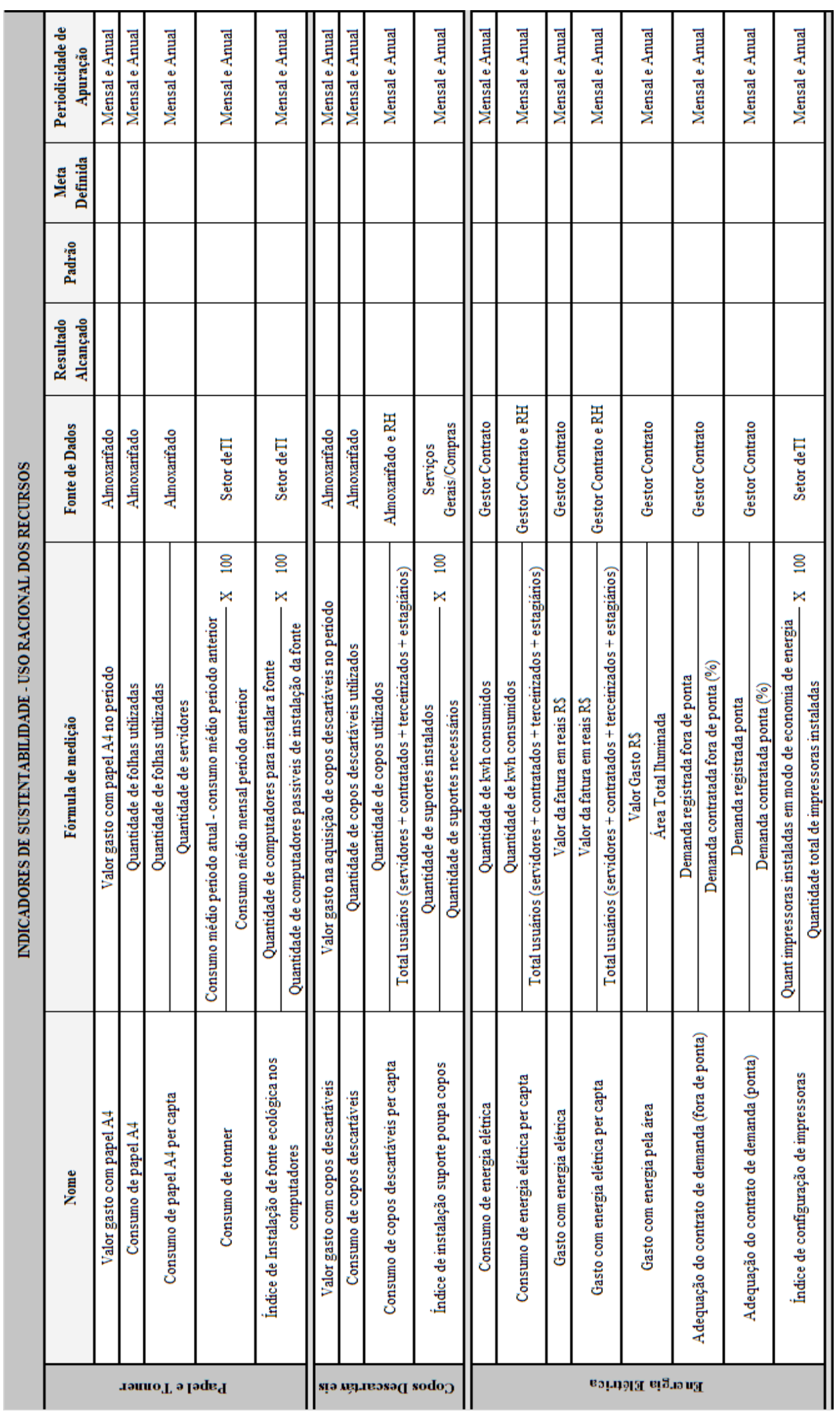

Rev. Adm. UfSM, Santa Maria, v. 8, Ed. Especial XVI ENGEMA, P. 08-27, 2015 


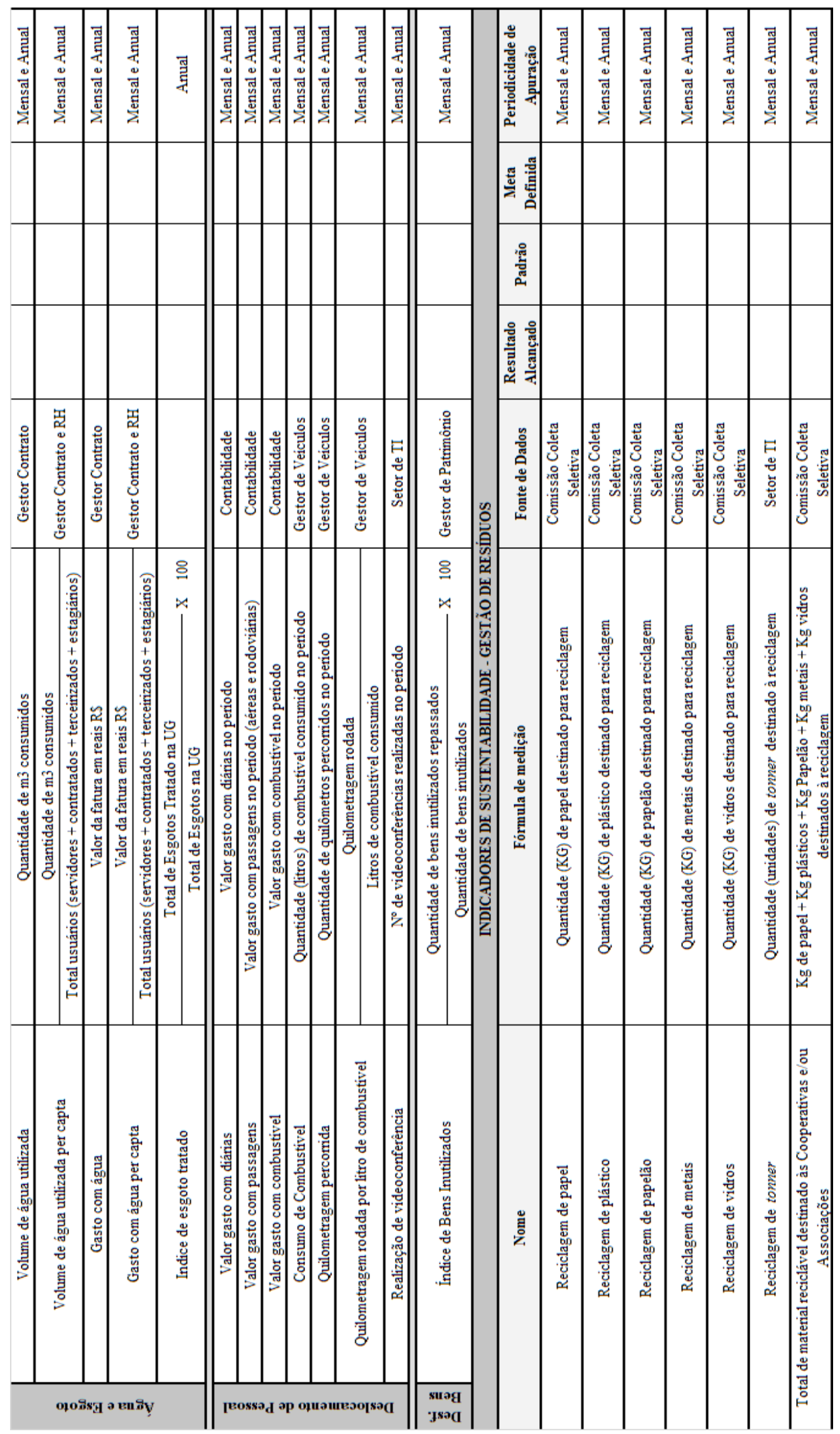

Rev. Adm. UfSM, SANTA Maria, v. 8, Ed. EsPecial XVI ENGEMA, P. 08-27, 2015 


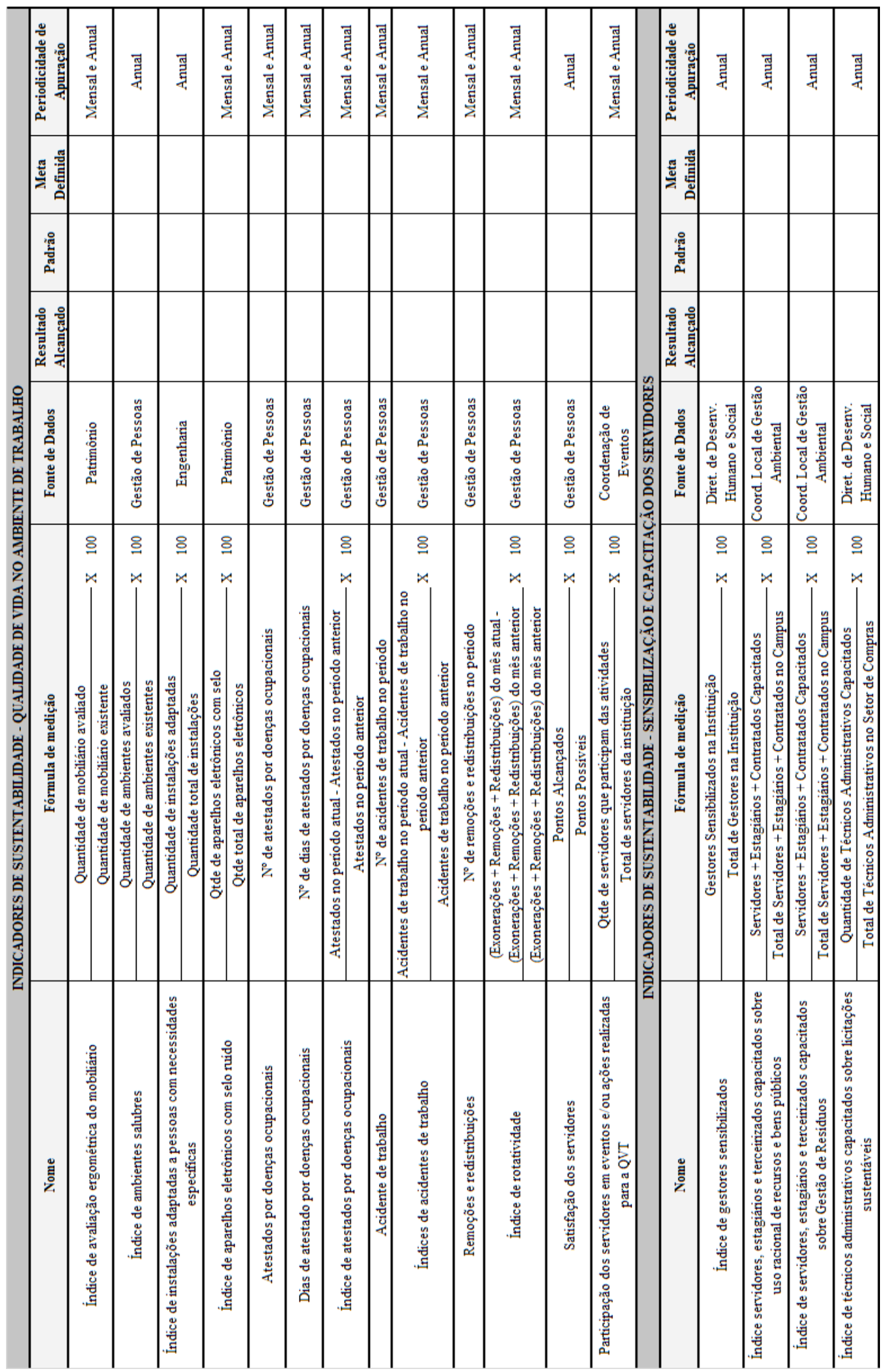




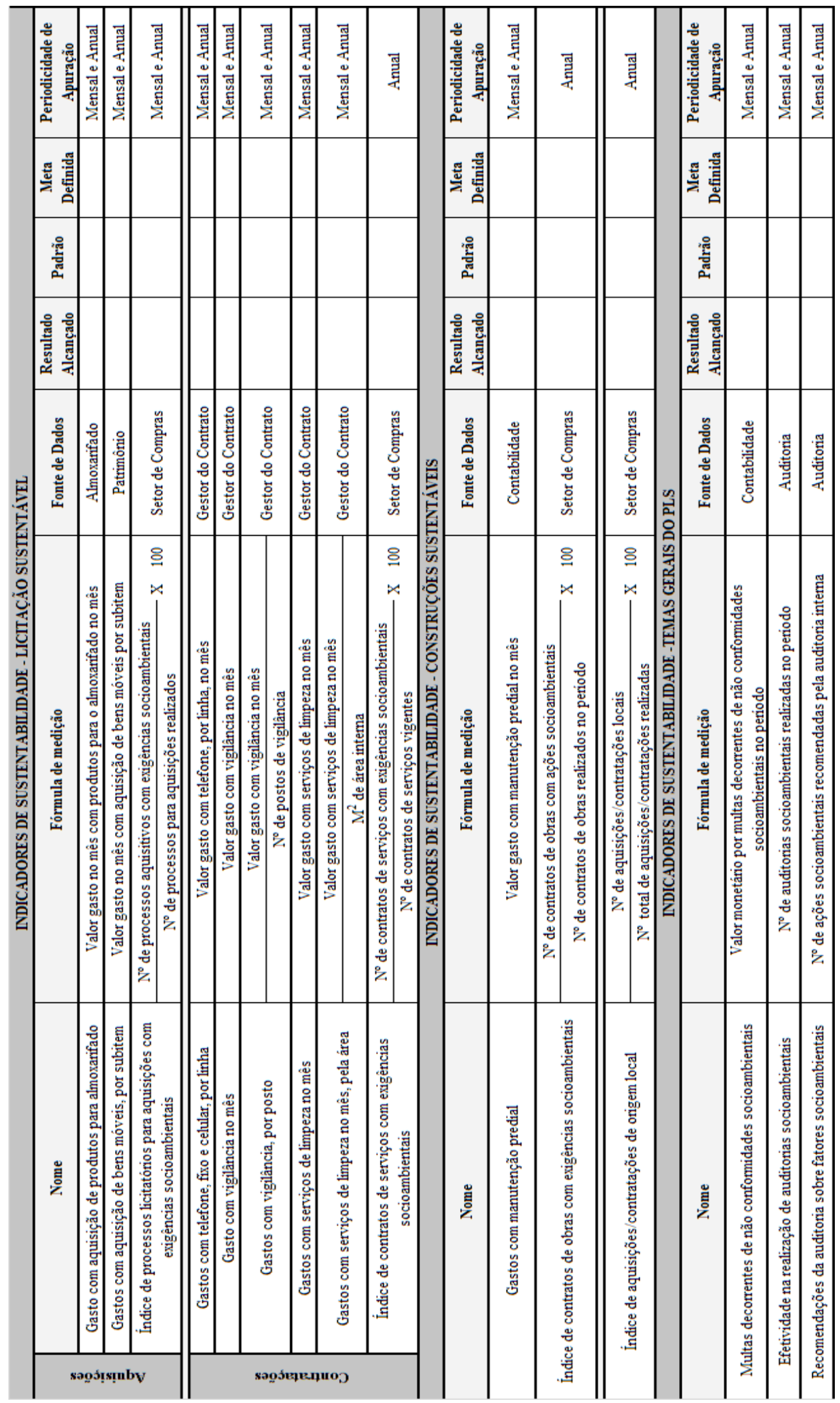

Fonte: elaborado pelos autores, com base em MMA (2009; 2014), Brasil (2012), BCB (2013), IF Sertão Pernambucano (2013), UF Paraíba (2013) e UF Alfenas (2013). 
Na estruturação dos indicadores socioambientais, foram incluídas três colunas além do solicitado na Instrução Normativa n. 10: a coluna do resultado alcançado, do padrão e da meta definida. A primeira coluna (resultado alcançado) refere-se ao resultado efetivamente alcançado na aplicação da fórmula de medição. Já a segunda (padrão) representa um valor mínimo aceitável. Este valor deve ser definido pelos Órgãos Superiores (Ministérios) ou Órgãos Reguladores (Tribunal de Contas da União e Controladoria Geral da União), após uma análise temporal dos resultados alcançados por órgãos com características semelhantes e em observância às políticas públicas e legislações cabíveis a cada situação. E a terceira coluna (meta), por sua vez, indica o valor desejado pela gestão do órgão para cada indicador, sempre respeitando o padrão mínimo estabelecido para cada situação.

O resultado alcançado versus a meta estabelecida pelo órgão é que vai auxiliar na análise dos resultados e indicar o nível de sustentabilidade da instituição, cuja avaliação qualitativa pode ser realizada com base o modelo apresentado no Quadro 5.

Quadro 5 - Análise dos resultados - resultado alcançado x meta definida

\begin{tabular}{|c|c|l|}
\hline $\begin{array}{c}\text { (Resultado alcançado / } \\
\text { meta definida) x } 100\end{array}$ & Sustentabilidade & $\begin{array}{r}\text { Desempenho: gera impacto, acompanhamento/controle e } \\
\text { tratamento/correção }\end{array}$ \\
\hline Até $20 \%$ & Péssimo & $\begin{array}{l}\text { A atividade causa impacto no meio ambiente, o acompanha- } \\
\text { mento é limitado/insuficiente, e o problema não é tratado. }\end{array}$ \\
\hline Entre $20 \%$ e $40 \%$ & Ruim & $\begin{array}{l}\text { A atividade causa impacto no meio ambiente, é realizado o } \\
\text { acompanhamento, mas o problema não é tratado. }\end{array}$ \\
\hline Entre $40 \%$ e $60 \%$ & Regular & $\begin{array}{l}\text { A atividade causa impacto no meio ambiente, o acompanha- } \\
\text { mento é limitado/insuficiente, mas há um tratamento brando. }\end{array}$ \\
\hline Entre $60 \%$ e $80 \%$ & Bom & $\begin{array}{l}\text { A atividade causa impacto no meio ambiente, é realizado o } \\
\text { acompanhamento, mas há poucas iniciativas para o tratamento. }\end{array}$ \\
\hline Acima de $80 \%$ & Ótimo & $\begin{array}{l}\text { A atividade causa impacto no meio ambiente, é realizado o } \\
\text { acompanhamento, e há muitas iniciativas para o tratamento. }\end{array}$ \\
\hline
\end{tabular}

Fonte: adaptado de Nunes (2010).

Na análise dos resultados, as comissões avaliadoras devem dedicar maior atenção para as situações em que o resultado alcançado indicar um índice de sustentabilidade péssimo ou ruim. Nestes casos, há necessidade de analisar detalhadamente as variáveis que influenciam diretamente o indicador, para identificar onde estão as deficiências no processo. Após identificar os pontos falhos ou as oportunidades de melhoria, procede-se à inclusão de novos itens no Plano de Ações, sempre observando o atendimento aos tópicos mínimos exigidos pela instrução normativa regulamentadora do PLS.

Um estudo mais detalhado sobre o PLS foi desenvolvido em formato de dissertação no Programa de Pós-graduação em Contabilidade da Universidade Federal de Santa Catarina (UFSC). Essa dissertação, cujo foco foi direcionado para Instituições da Rede Federal de Educação Profissional e Tecnológica, traz um rol mais amplo de ações e indicadores socioambientais, tendo sido escrita por Luiz (2014). Uma versão mais resumida e abrangente (pois traz apenas ações e indicadores aplicáveis à maioria dos órgãos públicos federais) foi apresentada no XVI Encontro Nacional sobre Gestão Empresarial e Meio Ambiente (ENGEMA), conforme Luiz e Dahmer Pfitscher (2014). 


\section{CONSIDERAÇÕES FINAIS E SUGESTÕES PARA FUTU- ROS ESTUDOS}

A gestão socioambiental vem se firmando como um relato obrigatório de elaboração e divulgação institucional. No final do ano de 2012, a gestão socioambiental alcançou os órgãos públicos federais brasileiros, que passaram a ser obrigados a elaborar e implementar o PLS e a divulgar os resultados alcançados periodicamente. Para regulamentar a elaboração do PLS, foi instituída uma instrução normativa que, dentre as determinações, define o conteúdo mínimo a estar contido no PLS, os temas mínimos a serem abrangidos e a forma de avaliação, que deve ocorrer por meio de indicadores.

Um dos conteúdos mínimos a compor o PLS consiste nas práticas de sustentabilidade e de racionalização no uso de materiais e serviços, que deve ser desenvolvido por meio do Plano de Ações Socioambientais, com indicação das ações a serem implementadas, dos envolvidos e dos responsáveis na implementação de cada ação, das metas a serem alcançadas, do cronograma de implementação e dos recursos necessários. Para o desenvolvimento do Plano de Ações, a instrução normativa também determinou alguns temas mínimos que devem ser abrangidos (material de consumo; energia elétrica; água e esgoto; coleta seletiva; qualidade de vida no ambiente de trabalho; compras e contratações sustentáveis; e deslocamento de pessoal). Assim, seguindo a estruturação dos seis eixos temáticos da A3P, o presente artigo traz um rol de ações socioambientais que podem ser aplicadas nos órgãos públicos federais, bem como a estruturação de um conjunto de indicadores socioambientais para mensurar os resultados alcançados, em observância ao padrão estabelecido para a construção dos indicadores no PLS.

Salienta-se que as proposições, tanto de ações como de indicadores, são sugestões comuns à maioria dos órgãos públicos, não esgotando, entretanto, todas as possibilidades. Cabe a cada órgão analisar suas atividades-fim e os impactos causados por estas no meio ambiente, bem como seus objetivos, para então definir seu Plano de Ações e seus indicadores.

Para realizar a análise dos resultados, a metodologia proposta confronta os resultados alcançados versus as metas definidas pela instituição. $O$ resultado obtido com a aplicação de uma formula remeterá a um percentual que indica o nível de sustentabilidade do órgão para cada indicador, o qual pode ser péssimo, ruim, regular, bom ou ótimo. Cabe à instituição analisar cada situação, dedicando maior atenção para os indicadores que evidenciarem um nível de sustentabilidade péssimo ou ruim, para então identificar os pontos falhos ou as oportunidades de melhoria e propor novas ações a serem implementadas se assim julgar necessário.

O presente estudo limita-se à proposição de algumas ações e indicadores socioambientais que podem ser incluídos no PLS dos órgãos públicos, além de uma metodologia para analisar os resultados alcançados. Assim sendo, para futuros estudos, sugere-se a ampliação do rol de ações e de indicadores socioambientais, bem como a aplicação do modelo em órgãos públicos federais, para analisar sua eficácia. Para os profissionais, acadêmicos e pesquisadores da área de Tecnologia da Informação, sugere-se uma possível informatização utilizando as fórmulas dos indicadores, de modo a facilitar a mensuração e análise dos resultados alcançados. 


\section{REFERÊNCIAS}

ALMEIDA, L. N. de. Sustentabilidade ambiental como estratégia empresarial na rede Walmart. In: SIMPÓSIO DE EXCELÊNCIA EM GESTÃO TECNOLOGICA, 7., 2010, Resende. Anais... Rio de Janeiro: AEBD, 2010. Disponível em: <http://www.aedb.br/seget/artigos10/235_ Sustentabilidade\%20Ambiental\%20e\%20 Estrategia\%20Empresarial\%20na\%20Rede\%20 Walmart.pdf>. Acesso em: 20 jan. 2014.

BANCO CENRAL DO BRASIL (BCB). Plano de Gestão de Logística Sustentável. 2013. Disponível em: <https://www.bcb.gov.br/adm/ plan/port/pdf/logisticasustentavel_042013. pdf $>$. Acesso em: 20 fev. 2014.

BELLEN, H. M. V. Indicadores de Sustentabilidade: uma análise comparativa. 2. ed. Rio de Janeiro: Editora FGV, 2006.

BRASIL. Decreto n. 5.940 , de 25 de outubro de 2006. Institui a separação dos resíduos recicláveis descartados pelos órgãos e entidades da administração pública federal direta e indireta, na fonte geradora, e a sua destinação às associações e cooperativas dos catadores de materiais recicláveis, e dá outras providências. Disponível em: <http:// www.planalto.gov.br/ccivil_03/_Ato20042006/2006/Decreto/D5940.htm>. Acesso em: 1ㅇ ago. 2015.

BRASIL. Secretaria de Logística e Tecnologia da Informação do Ministério do Planejamento (SLTI/MP). Instrução Normativa n.ㅇ 01, de 19 de janeiro de 2010. Dispõe sobre os critérios de sustentabilidade ambiental na aquisição de bens, contratação de serviços ou obras pela Administração Pública Federal direta, autárquica e fundacional e dá outras providências. Disponível em: <http://www. comprasnet.gov.br>. Acesso em: 08 set. 2013.

BRASIL. Lei n.o 12.305, de 02 de agosto de 2010. Institui a Política Nacional de Resíduos Sólidos; altera a Lei nํ 9.605, de 12 de fevereiro de 1998; e dá outras providencias. Disponível em: <http://www.planalto.gov.br/ccivil_03/_ ato2007-2010/2010/lei/l12305.htm>. Acesso em: 1ㅇago. 2015 .

BRASIL. Decreto n.․ 7.746, de 05 de junho de 2012. Regulamenta o art. 3o da Lei no 8.666, de 21 de junho de 1993, para estabelecer critérios, práticas e diretrizes para a promoção do desenvolvimento nacional sustentável nas contratações realizadas pela administração pública federal, e institui a Comissão Interministerial de Sustentabilidade na Administração Pública - CISAP. Disponível em: <http://www.planalto.gov.br/ccivil_03/_ Ato2011-2014/2012/Decreto/D7746.htm>. Acesso em: 03 out. 2013.

BRASIL. Secretária de Logística e Tecnologia da Informação do Ministério do Planejamento, Orçamento e Gestão. Instrução Normativa no 10, de 12 de novembro de 2012. Estabelece regras para elaboração dos Planos de Gestão de Logística Sustentável de que trata o art. 16, do Decreto no 7.746 , de 5 de junho de 2012, e dá outras providências. Disponível em: <http://cpsustentaveis.planejamento. gov.br/wp-content/uploads/2012/11/ Instru\%C3\%A7\%C3\%A3o-Normativa-10-2012. pdf.>. Acesso em: 03 out. 2013.

CAMPOS, L. M. de S., MELO, D. A. de. Indicadores de desempenho dos sistemas de gestão ambiental (SGA): Uma pesquisa teórica. Produção, v. 8, n. 3, p. 540-555, 2008.

COOPER, T. Slower Consumption. Journal of Industrial Ecology, v. 9, n. 1-2, p. 51-67, 2005.

DIAS, R. Gestão ambiental: Responsabilidade social e sustentabilidade. São Paulo: Atlas, 2006.

ENGELMAN, R.; GUISSO, R. M.; FRACASSO, E. $M$. Ações de gestão ambiental nas instituições de ensino superior: $O$ que tem sido feito. Revista de Gestão Social e Ambiental, v. 3, n. 1, p. 22-33, 2009.

FARIAS, C. A. et al. No limiar da quarta revolução 
industrial: iniciativas para sustentabilidade por empresas líderes do setor automotivo rumo à nova economia. Revista de Administração FACES, v. 12, n. 3, p. 82-95, 2013.

FOCHT, W.; ABRAMSON, C. I. The case for Interdisciplinary Environmental Education and Research. American Journal of Environmental Sciences, v. 5, n. 2, p. 124-129, 2009.

FONSECA, A. et al. The state of sustainability reporting at Canadian universities. International Journal of Sustainability in Higher Education, v. 12, n. 1, p. 22- 40, 2011.

FREITAS, C. L. Avaliação de sustentabilidade em instituições públicas federais de ensino superior (IFES): proposição de um modelo baseado em sistemas gerenciais de avaliação e evidenciação socioambiental. 2013. 187f. Dissertação (Mestrado em Contabilidade) - UniversidadeFederal de Santa Catarina, Florianópolis, 2013.

GALLOPÍN, G. C. Environmental and sustainability indicators and the concept of situational indicators: A systems approach. Environmental Modeling \& Assessment, v. 1, n. 3, p. 101-117, 1996.

GIL, A. C. Como elaborar projetos de pesquisa. 4. ed. São Paulo: Atlas, 2007.

GROSBOIS, D. Corporate social responsibility reporting by the global hotel industry: Commitment, initiatives and performance. International Journal of Hospitality Management, v. 31, p. 896-905, 2012.

HOBSBAWM, E. A era dos extremos: o breve século XX-1914-1991. São Paulo: Schwarcz, 1996.

INSTITUTO FEDERAL DE EDUCAÇÃO, CIÊNCIA E TECNOLOGIA DO SERTÃO PERNAMBUCANO. Plano de Gestão de Logística Sustentável: Biênio 2013-2014. 2013. Disponível em: <http://www. ifsertao-pe.edu.br/reitoria/images/ascom/ PRODI/plano\%20de\%20logstica\%20sustentvel. pdf>. Acesso em: 20 fev. 2014.
JACOBI, P. Educação ambiental, cidadania e sustentabilidade. Cadernos de Pesquisa, n. 118, p. 189-205, mar. 2003.

KRAJNC, D.; GLAVIC, P. Indicators of Sustainable Production. Clean Techn Environ Policy, v. 5, p. 279-288, 2003.

LUIZ, L. C. et al. Agenda Ambiental na Administração Pública (A3P) e práticas de sustentabilidade: Estudo aplicado em um Instituto Federal de Educação, Ciência e Tecnologia. Administração Pública e Gestão Social, v. 5, n. 2, p. 114-134, 2013.

LUIZ, L. C. Plano de Gestão de Logística Sustentável: proposta de um modelo para avaliação do desempenho socioambiental em Instituições da Rede Federal de Educação Profissional e Tecnológica. 2014. $198 \mathrm{f}$. Dissertação (Mestrado em Contabilidade) - Universidade Federal de Santa Catarina, Florianópolis, 2014.

LUIZ, L. C.; DHAMER PFITSCHER, E. Plano de Gestão de Logística Sustentável: Proposição de Ações e Indicadores Socioambientais para Avaliar - Desempenho nos Órgãos Públicos Federais. In: ENCONTRO NACIONAL SOBRE GESTÃO EMPRESARIAL E MEIO AMBIENTE, 16., 2014, São Paulo. Anais... São Paulo: FEAUSP, 2014.

MACIEL, D. S. C.; FREITAS, L. S. Utilização do Método FMEA na Identificação e Análise dos Impactos Ambientais Causados pelos Postos de Combustível: um estudo de caso. Revista de Administração da UFSM, v. 7, n. 4, p. 570-589, 2014.

MINISTÉRIO DO MEIO AMBIENTE (MMA). Agenda Ambiental na Administração Pública (A3P). 5. ed. Brasília: MMA, 2009. Disponível em: <http://www.mma.gov.br/ responsabilidade-socioambiental/a3p/>. Acesso em: 12 set. 2013.

. Indicadores de Desempenho da A3P.

Disponível em: <http://www.mma.gov.br/ images/arquivo/80063/Indicadores\%20da\%20 
A3P-versao\%20final.pdf>. Acesso em: 25 mai. 2014.

Eixos Temáticos da A3P. Disponível em: <http://www.mma.gov.br/responsabilidadesocioambiental/a3p/eixos-tematicos>. Acesso em 04 ago. 2015.

NUNES, J. P. O. Um aporte ao sistema contábil gerencial ambiental: elaboração e aplicação parcial do novo sistema em clínica hospitalar. 2010. 241 f. Dissertação (Mestrado em Contabilidade) - Universidade Federal de Santa Catarina, Florianópolis, 2010.

PERERIRA, J. C. R. Análise de dados Qualitativos: estratégias metodológicas para as ciências da saúde, humanas e sociais. 3. ed. São Paulo: Editora da Universidade de São Paulo, 2001.

ODA, M. et al. Logística Sustentável: contribuição a processos de gestão. Interfacehs: Revista de Gestão Integrada em Saúde do Trabalho e Meio Ambiente, v. 4, n. 1, p. 1-26, 2009.

RAUPP, F. M.; BEUREN, I. M. Metodologia de Pesquisa Aplicável às Ciências Sociais. In: BEUREN, I. M. (Org.) Como Elaborar Trabalhos Monográficos em Contabilidade: teoria e prática. 3. ed. São Paulo: Atlas, 2009. p. 76-97.

RIBEIRO, R. R. M. Evolução das pesquisas em Contabilidade Gerencial: uma análise das opções temáticas e abordagens metodológicas no Brasil. 2011. 120 f. Dissertação (Mestrado em Contabilidade) - UniversidadeFederal do Paraná, Curitiba, 2011.

RICHARDSON, R. J. Pesquisa Social: métodos e técnicas. 3. ed. ver. e ampl. São Paulo: Atlas, 2008.

SILVA, M. E.; ALVES, A. P. F.; VOLKMER, G. Está Chovendo no Molhado? A visão acadêmica sobre o desenvolvimento sustentável em um contexto de crise. Revista de Administração da UFSM, v. 7, ed. especial, p. 70-87, 2014.

SOARES, A. C. B. et al. A Gestão Socioambiental em Pauta: a análise do caso de uma rede de supermercados da região central do RS. Revista de Administração da UFSM, v. 7, ed. especial, p. 113-126, 2014.

TEIXEIRA, M. F. de F. B. Desafios e Oportunidades para a Inserção do Tripé da Sustentabilidade nas Contratações Públicas: Um estudo dos Casos do Governo Federal Brasileiro e do Governo do Estado de São Paulo. 2013. 312 f. Dissertação (Mestrado em Desenvolvimento Sustentável) Universidade de Brasília, Brasília, 2013.

TIMOSSI, L. da S. Correlação entre a qualidade de vida e a qualidade de vida no trabalho em colaboradores das indústrias de laticínios. 2009. 180 f. Dissertação (Mestrado em Engenharia de Produção) - Universidade Tecnológica Federal do Paraná, Ponta Grossa, 2009.

UNITED NATIONS ENVIRONMENT PROGRAMME (UNEP). UNEP Year Book 2012: Emerging Issues in our Global Environment. United Kingdom: UNEP, 2012.

UNIVERDIDADE FEDERAL DE ALFENAS (UNIFAL). Plano de Logística Sustentável - PLS. 2013. Disponível em: <http://www.unifal-mg. edu.br/portal/arquivos/pls-unifal-mg.pdf $>$. Acesso em: 20 fev. 2014.

UNIVERSIDADE FEDERAL DE PARAÍBA. Comissão de Gestão Ambiental. Plano de Logística Sustentável (2013-2015). 2013. Disponível em: <http://www.ufpb.br/cga/wpcontent/uploads/2013/06/Plano-de-logisticasustentavel-Atual-06-06-Minuta2.pdf >. Acesso em: 20 fev. 2014.

WORLD COMMISSION ON ENVIRONMENT AND DEVELOPMENT (WCED). Our common future (The Brundtland Report). Oxford: OUP, 1987. Disponível em: <http://www.un-documents. net/ocf-02.htm\#l>. Acesso em: 05 jan. 2014.

WIDMER, R. et al. Global perspectives on e-waste. Environmental Impact Assessment Review, v. 25, n. 5, p. 436-458, 2005. 